\title{
ANALISIS KINERJA PELAT BESI BERKARAT OLEH RUST REMOVER $X$
}

\author{
Ferry Budhi Susetyo, Munzir Qadri, Fadwah Maghfurah, Sulis Yulianto \\ Jurusan Teknik Mesin, Fakultas Teknik, Universitas Muhammadiyah Jakarta \\ Email: fbudhi@unj.ac.id,flash_mq@yahoo.com,fmaghfurah@yahoo.com, \\ sulis.yulianto@yahoo.com
}

\begin{abstract}
ABSTRAK
Rust remover akan menghilangkan seluruh karat dari permukaan logam. Terdapat tiga metode dari rust remover yaitu: rust remover berbahan dasar asam (acid base), shoot blasting dan rust remover $X$. Rust remover $X$ adalah sebuah produk yang berbahan dasar air (water based) sehingga relatif aman, efektif serta tidak berbahaya bagi lingkungan. Tujuan dari penelitian ini adalah mengetahui kapan waktu rust remover $X$ bekerja maksimal serta fasa-fasa apa yang ada sebelum dan setelah perendaman di rust remover X. Metodologi penelitian karakterisasi spesimen dengan menggunakan SEM, XRF dan XRD. Untuk karakterisasi XRD dilakukan sebelum dan sesudah perendaman. Kesimpulan penelitian ini adalah fasa-fasa pelat besi, sebelum di rendam adalah $\mathrm{Fe} 28,2 \%, \mathrm{Fe}_{3} \mathrm{O}_{4}$ 25,96 \%, $\mathrm{SiO}_{2}$ 39,43\%, dan $\mathrm{FeO}_{2} 6,4$ $\%$, fasa pelat besi, setelah di rendam adalah $\mathrm{Fe} 100 \%$, waktu rust remover $X$ bekerja maksimal antara 60 menit sampai 90 menit.
\end{abstract}

Kata Kunci : Korosi, besi, $X$ Rust Remover

\begin{abstract}
Rust remover will lost all of the rust from the surface of metal. There are three type of the rust remover product: acid base rust remover, shoot blasting (sand blasting) and $X$ rust remover. $X$ rust remover is water based product, effective also save for environtment. Aim of the research are to know when rust remover $X$ work best, and phases before and after immerse to $X$ rust remover. Methodology this research are characterization specimen with SEM, XRF and XRD. For XRD characterization is do before and after immerse. Conclusions the research are iron phases before immerse are $\mathrm{Fe} 28,2 \%, \mathrm{Fe}_{3} \mathrm{O}_{4} 25,96 \%$, $\mathrm{SiO}_{2}$ 39,43\%, dan $\mathrm{FeO}_{2}$ 6,4 \%, iron phases after immerse is $\mathrm{Fe} 100 \%$, rust remover X work best between 60 minutes until 90 minutes.
\end{abstract}

Key Word : Corrosion, Iron, X Rust Remover

\section{PENDAHULUAN}

Korosi merupakan fenomena kerusakan suatu material akibat material tersebut bereaksi secara kimia dengan lingkungan yang tidak mendukung. Korosi dapat berlangsung apabila semua komponen sel elektrokimia tersedia yaitu anoda, katoda sirkuit eksternal (penghubung antara anoda dan katoda), sirkuit internal (elektrolit). (Ashadi, 2002)

Rust remover akan menghilangkan seluruh karat dari permukaan logam. Terdapat tiga metode dari rust remover yaitu: rust remover berbahan dasar asam (acid base), shoot blasting dan rust remover $\mathrm{X}$. Metode pertama adalah menghilangan karat dengan menggunakan rust remover acid base, metode ini memiliki kekurangan yaitu memerlukan tambahan biaya dalam penggunaanya seperti memerlukan alat pelindung diri. Kemudian metode yang kedua adalah metode sand blasting, metode ini dapat melemahkan properties dari material karena aplikasinya dengan benturan mekanis melalui media pasir silika. Kedua metode penghilangan karat yaitu metode rust remover acid base dan metode sand blasting berbahaya bagi kesehatan serta membutuhkan prosedur yang khusus dalam pengolahan limbahnya. (GDP Rust Remover X Sales Kit, 2006)

Rust remover $\mathrm{X}$ adalah sebuah produk yang berbahan dasar air (water based) sehingga relatif aman, efektif serta tidak berbahaya bagi lingkungan (Rust Remover X Technical Data Sheet). Untuk itu maka akan dilakukan penelitian secara akademisi guna mengetahui kapan 
waktu rust remover $X$ bekerja maksimal serta fasa-fasa apa yang ada sebelum dan setelah perendaman di rust remover $X$.

Korosi merupakan proses alamiah. Seperti air mengalir ke permukaan yang lebih rendah, seluruh proses alamiah akan bergerak ke arah energi yang lebih rendah. Jadi besi dan baja memiliki kecenderungan untuk bergabung dengan elemen kimia lainnya untuk bergerak ke energi yang lebih rendah. Besi dan baja akan sering berikatan dengan oksigen, membentuk iron oxide atau karat memiliki susunan kimia yang sama dengan iron ore. Gambar 1. menunjukkan ilustrasi dari siklus dari pemurnian korosi dari besi dan baja. (Jenkins, 2005)

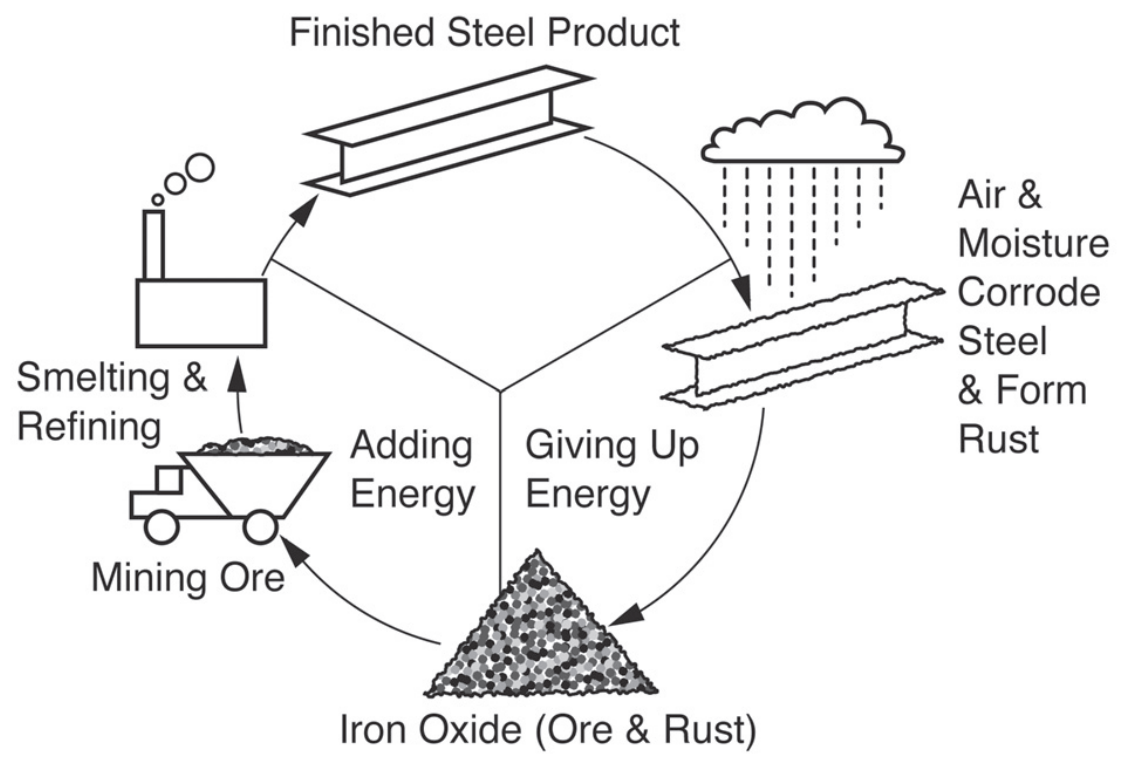

Gambar 1. Siklus Korosi. (Jenkins, 2005)

Logam dan paduan lain ketika dalam kondisi energi yang tinggi mereka dalam bentuk logam resistan terhadap korosi yang terbentuk lapisan pasif (biasanya oksida) pada permukaan. Lapisan tersebut terbentuk melalui proses alami yang menyerupai korosi dan biasanya tidak terlihat dengan menggunakan mata telanjang. Stainless steel, paduan alumunium dan titanium adalah logam yang memiliki kondisi energi tinggi pada saat berbentuk logam. Namun relatif resistan pada korosi disebabkan oleh bentuk lapisan pasif pada permukaannya. Bagaimanapun khususnya pada kasus stainless steel dan paduan alumunium lapisan ini tidak kebal pada seluruh lingkungan natural dan dapat rusak pada satu atau lebih lingkungan khusus. Kerusakan lapisan pasif sering berlangsung sangat cepat, korosi yang terlokalisir disebabkan oleh aktifitas elektrokimia bagian dari permukaan yang tetap pasif. (Jenkins, 2005)

Rust remover $X$ bekerja melalui selektif chelating agent pada $\mathrm{pH}$ 6,0 sampai 7,1 (netral). Proses ini dimana molekul sintesis dalam jumlah besar membentuk ikatan dengan logam dan menahan mereka dalam larutan. Kebanyakan chelating agent mengikat berbagai macam metal. Unsur aktif dalam rust remover X mengikat besi secara eksklusif. Unsur aktif tersebut dapat melepas besi dari iron oxide tetapi terlalu lemah untuk melepas besi dari baja, dimana baja memiliki ikatan yang lebih kuat. Sekali chelating agent melepas besi kemudian molekul organik sulfur menarik besi jauh dari chelator dan membentuk ferritic sulfate kompleks. Chelating agent yang bebas dapat kembali melepas besi dari karat.

\section{METODE PENELITIAN}

Bahan yang digunakan dalam penelitian ini adalah pelat besi berkarat yang belum diketahui jenisnya. Pelat besi yang berkarat dengan ketebalan 1,2 $\mathrm{mm}$ kemudian dipotong dengan dimensi seperti pada Gambar 2. 


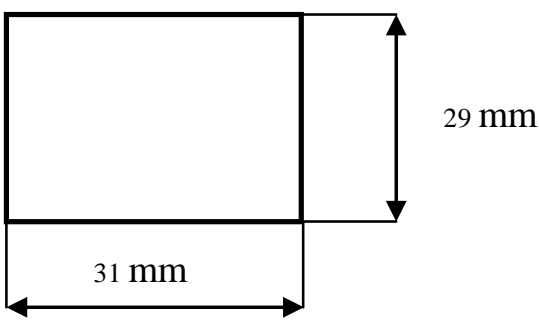

\section{Gambar 2. Dimensi Spesimen Pelat Berkarat}

Mula-mula spesimen pelat besi berkarat dilakukan karakterisasi menggunakan XRF guna mengetahui komposisi unsur dari spesimen. Setelah diketahui kemudian dilakukan karakterisasi dengan menggunakan XRD guna mengetahui fasa yang terjadi.

Spesimen yang telah dikarakterisasi dengan menggunakan XRF dan XRD kemudian direndam dalam $240 \mathrm{ml}$ cairan rust remover $X$. Kemudian dilakukan pengukuran pengurangan massa spesimen dengan interval waktu 30 menit selama empat jam menggunakan timbangan Bosc SAE 200. Setelah selesai dilakukan pengukuran pengurangan massa kemudian dikarakterisasi kembali dengan menggunakan XRD.

\section{HASIL DAN PEMBAHASAN}

Dari data XRD sebelum pelat besi berkarat direndam selama empat jam dapat dilihat bahwa fraksi berat fasa $\mathrm{Fe}$ adalah $28,2 \%, \mathrm{Fe}_{3} \mathrm{O}_{4}$ adalah $25,96 \%$, $\mathrm{SiO}_{2}$ adalah 39,43\%, dan $\mathrm{FeO}_{2}$ adalah 6,4 \%. Dapat dilihat lengkap pada Gambar 3.

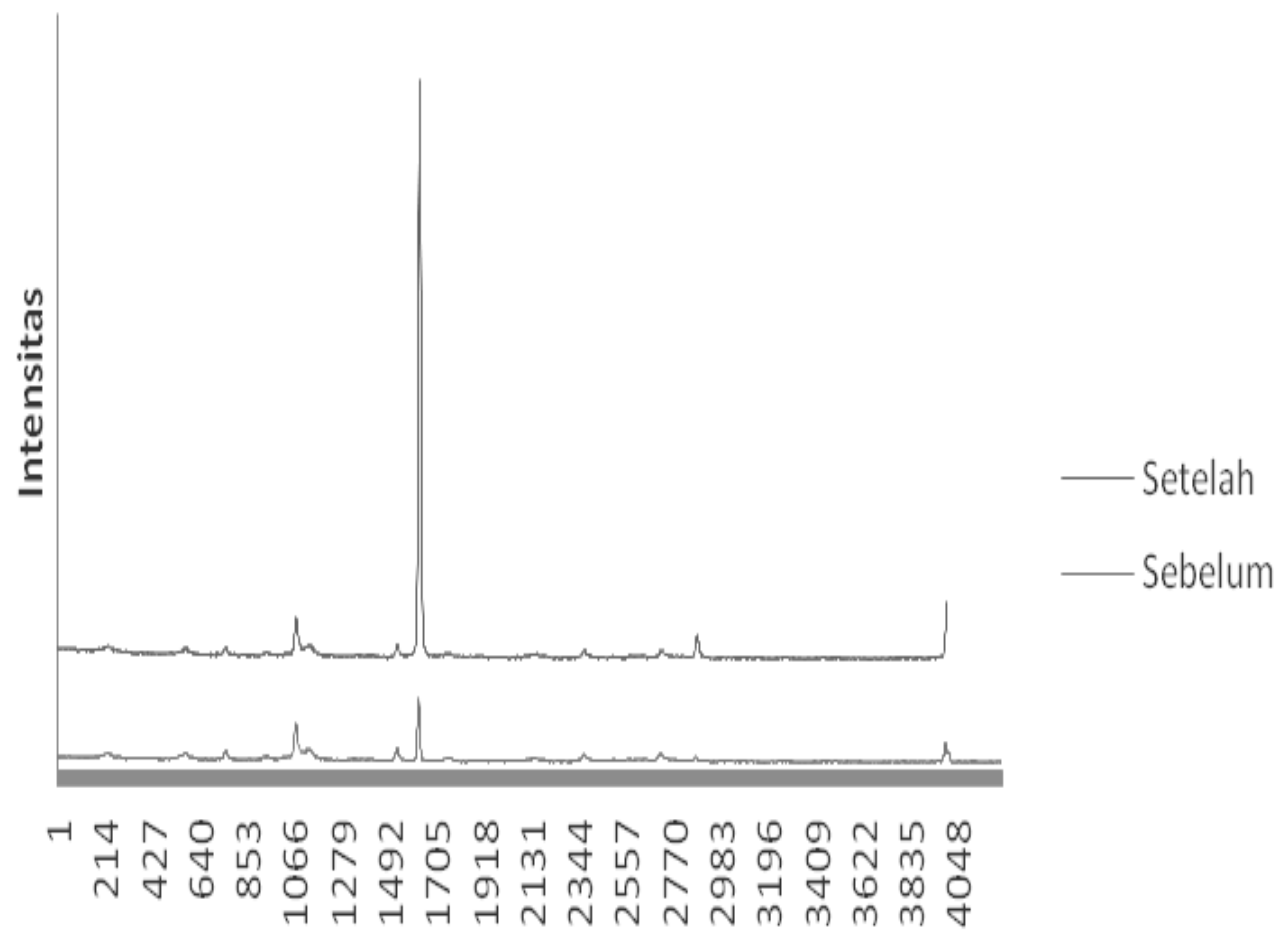

$2 \theta$

Gambar 3. Grafik Intensitas Terhadap 20 Setelah dan Sebelum Pelat Besi Berkarat Direndam 
Setelah pelat besi berkarat direndam selama empat jam maka tidak terlihat lagi fasa $\mathrm{SiO}_{2}$. Hal ini disebabkan karena fasa $\mathrm{SiO}_{2}$ berada pada permukaan fasa $\mathrm{Fe}_{3} \mathrm{O}_{4}$ dan $\mathrm{FeO}_{2}$, sehingga ketika atom $\mathrm{Fe}$ pada $\mathrm{Fe}_{3} \mathrm{O}_{4}$ dan $\mathrm{FeO}_{2}$ dilepas oleh chelating agent, fasa $\mathrm{SiO}_{2}$ ikut terlepas dari permukaan $\mathrm{Fe}_{3} \mathrm{O}_{4}$ dan $\mathrm{FeO}_{2}$. Chelating agent hanya mengikat $\mathrm{Fe}$ yang kemudian akan bersenyawa dengan S sehingga akan timbul ikatan FeS. Pada analisis ini FeS tidak terdeteksi, karena senyawa FeS berada pada endapan cairan rust remover $X$.

Pengukuran pengurangan massa ini dilakukan guna mengetahui berapa besar pengurangan massa dengan interval waktu 30 menit. Metodenya yaitu, spesimen tersebut direndam selama empat jam, kemudian setiap 30 menit dilakukan pengukuran massa. Luas permukaan sampel (1) dan sampel (2) masing-masing adalah $1942 \mathrm{~mm}^{2}$. Hasil dari pengukuran massa dapat dilihat pada grafik sebagai berikut.

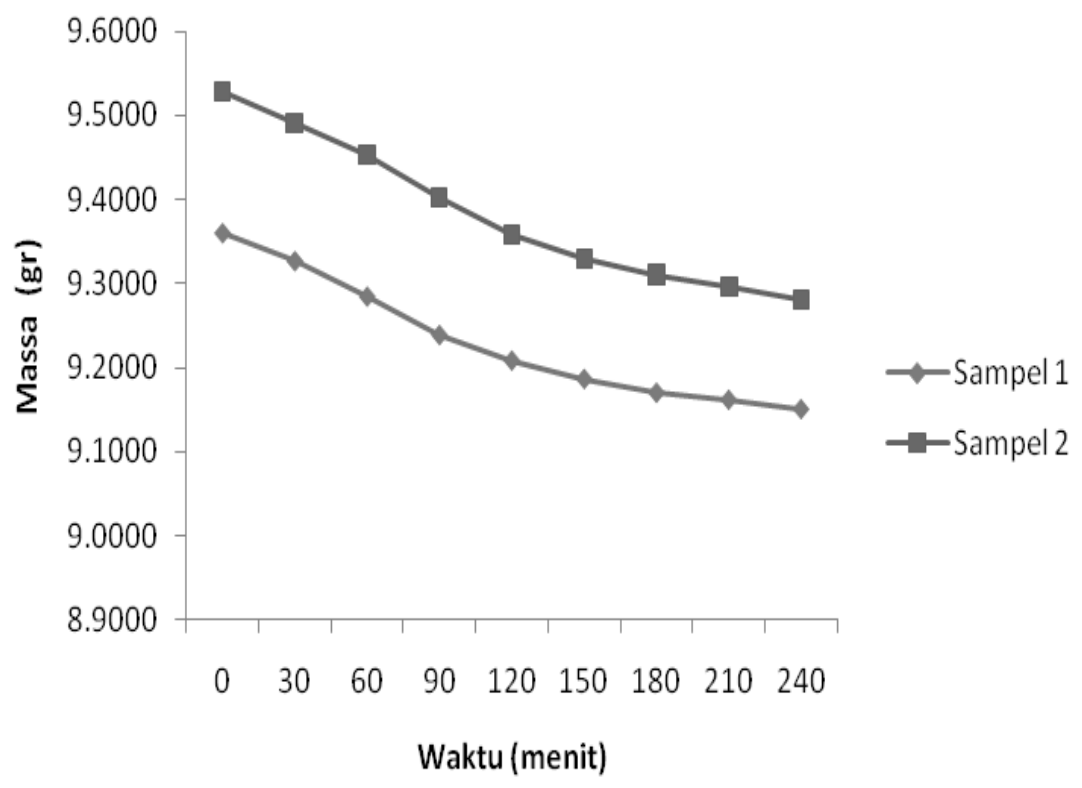

Gambar 4. Grafik Massa vs Waktu Perendaman Pelat Besi Berkarat

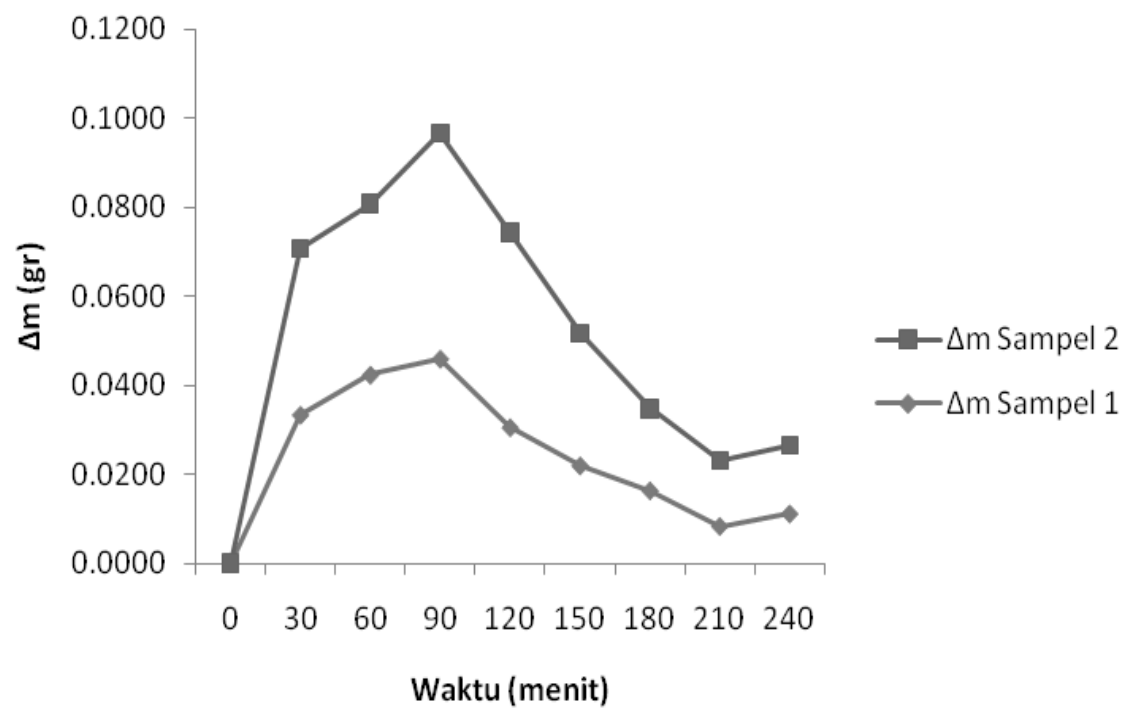

Gambar 5. Grafik $\Delta \mathrm{m}$ vs Waktu Perendaman Pelat Besi Berkarat 
Berdasarkan Gambar 5 di atas dapat dinyatakan bahwa waktu rust remover $X$ bekerja maksimal antara 60 menit sampai 90 menit. Sedangkan untuk selanjutnya rust remover $X$ akan menurun kinerjanya, namun pada 210 menit hingga 240 terjadi kenaikan kinerja kembali namun tidak signifikan jika dibandingkan dengan rentang waktu 60 menit sampai 90 menit.

\section{KESIMPULAN}

Setelah dilakukan penelitian serta analisis hasil dan pembahasan maka dapat disimpulkan sebagai berikut:

1. Fraksi berat awal fasa $\mathrm{Fe} 28,2 \%, \mathrm{Fe}_{3} \mathrm{O}_{4} 25,96 \%, \mathrm{SiO}_{2} 39,43 \%$, dan $\mathrm{FeO}_{2} 6,4 \%$. Setelah direndam selama empat jam fasa $\mathrm{SiO}_{2}$ sudah tidak terlihat karena fasa $\mathrm{SiO}_{2}$ berada pada permukaan fasa $\mathrm{Fe}_{3} \mathrm{O}_{4}$ dan $\mathrm{FeO}_{2}$ sehingga ketika atom $\mathrm{Fe}$ pada $\mathrm{Fe}_{3} \mathrm{O}_{4}$ dan $\mathrm{FeO}_{2}$ dilepas oleh chelating agent, fasa $\mathrm{SiO}_{2}$ ikut terlepas dari permukaan $\mathrm{Fe}_{3} \mathrm{O}_{4}$ dan $\mathrm{FeO}_{2}$. Chelating agent hanya mengikat $\mathrm{Fe}$ yang kemudian akan bersenyawa dengan $\mathrm{S}$ sehingga akan timbul ikatan FeS. Pada analisis ini FeS tidak terdeteksi, karena senyawa FeS berada pada endapan cairan rust remover $X$.

2. Waktu rust remover $X$ bekerja maksimal antara 60 menit sampai 90 menit. Sedangkan untuk selanjutnya rust remover $\mathrm{X}$ akan menurun kinerjanya, namun pada 210 menit hingga 240 terjadi kenaikan kinerja kembali namun tidak signifikan jika dibandingkan dengan rentang waktu 60 menit sampai 90 menit.

\section{DAFTAR REFERENSI}

[1] Anonim. "Rust Remover X Technical Data Sheet" Harris International Laboratories, Inc

[2] Anonim. (2006) “GDP Rust Remover X Sales Kit” Harris International Laboratories, Inc

[3] Ashadi , Henki W., W, Sulistyoweni, Gusniani, Irma (2002). "Pengaruh UnsurUnsur Kimia Korosif Terhadap Laju Korosi Tulangan Beton II. Di Dalam Lumpur Rawa”.

[4] ASTM A380 (2000) "Standard Practice for Cleaning, Descaling, and Passivation of Stainless Steel Parts, Equipment, and Systems”

[5] Chelation http://en.wikipedia.org/wiki/Chelating

[6] Fontana, M.G. (1986) “Corrosion Engineering”, McGraw Hill, New York.

[7] G.,Wyckoff R. W. (1963), "Second edition. Interscience Publishers, New York, New York Sample at $\mathrm{T}=298 \mathrm{~K}$ Body centered cubic, bcc, structure", Crystal Structures 1, 7-83

[8] H. E., King, C. T., Prewitt, (1982) "High-pressure and high-temperature polymorphism of iron sulfides (FeS) Sample: $\mathrm{T}=294 \mathrm{~K}, \mathrm{P}=0.0001 \mathrm{GPa}$, Acta Crystallographica, Section B 38, 1877-1887

[9] H., Fjellvag, F., Gronvold, S., Stolen, C., Hauback B. (1996) "On the crystallographic and magnetic structures of nearly stoichiometric iron monoxide Locality: synthetic Sample: T = 298 K", Journal of Solid State Chemistry 124, 5257

[10] Jenkins, James F., Drisko, Richard W. (2005)” Bridge Construction Manual” K., Kihara, (1990)"An X-ray study of the temperature dependence of the quartz structure Sample: at T $=298$ K", European Journal of Mineralogy 2, 63-77

[11] T., Nagai, H., Kagi, T., Yamanaka, (2003) "Variation of hydrogen bonded O...O distances in goethite at high pressure Sample at $\mathrm{P}=0 \mathrm{GPa}$ ", American Mineralogist 88, 1423-1427

[12] W., Sulistyoweni, Ashadi, Henki W.,Wicaksono, Andri Krisnadi (2002). "Pengaruh Unsur-Unsur Kimia Korosif Terhadap Laju Korosi Tulangan Beton I. Di Dalam Air Rawa”. 